\title{
OPTIMALISASI PENCAHAYAAN ALAMI DENGAN USEFULDAYLIGHT ILLUMINANCE PADA DESAIN RUMAH TOKO (RUKO) DI KOTA LHOKSEUMAWE
}

\author{
Atthaillah', Amril Bakhtiar², Badriana3 \\ 1,2Program Studi Arsitektur Universitas Malikussaleh, \\ ${ }^{3}$ Jurusan Teknik Elektro Universitas Malikussaleh \\ e-mail: *1atthaillah@unimal.ac.id, ${ }^{2}$ bakhtiaramril@yahoo.co.id,3badriana@unimal.ac.id
}

\begin{abstract}
Abstrak_Penelitian ini menawarkan proposal Rumah Toko (Ruko) di Kota Lhokseumawe yang ramah terhadap cahaya alami, sehingga berkonsekuensi langsung untuk pengurangan energi. Metode yang digunakan adalah melakukan simulasi komputer dengan menggunakan antar muka Rhinoceros, Grasshopper, Ladybug dan Honeybee. Climate based daylight modeling (CBDM) dengan metrik Useful Daylight Illuminance (UDI) digunakan untuk membuktikan pengoptimalan cahaya alami yang sesuai dengan Kota Lhokseumawe. Metrik UDI digunakan pada studi ini karena beberapa alasan, pertama, metrik ini menggunakan data meteorologi lokasi spesifik untuk simulasi pengukuran sehingga hasil yang diharapkan lebih akurat sesuai dengan lokasi geografis objek penelitian. Kedua, metrik ini membuat kategori batas tidak memenuhi karena kurang cahaya yaitu kurang dari 100 Lux, range optimal antara 100-2000 Lux serta batas kelebihan cahaya diatas 2000 Lux. Hal ini tentunya mendukung analisa hasil yang lebih baik dibandingkan dengan metrik Daylight Autonomy (DA) yang hanya menentukan batas bawah saja. Diantara strategi-strategi yang kami implementasikan untuk memperbaiki kondisi pencahayaan alami adalah substraksi bangunan, efisiensi organisasi ruang, memberbesar window wall ratio (WWR), kulit ganda dan shading devices. Hasil menunjukkan pencahayaan alami yang optimal dapat ditingkatkan dari 22 persen, pada Ruko eksisting, menjadi 73 persen per tahun pada desain proposal penelitian ini.
\end{abstract}

Kata Kunci: Pencahayaan Alami; Useful Daylight Illuminance (UDI); Ruko; Rhinoceros \& Grasshopper; Ladybug \& Honeybee

\begin{abstract}
This study offered a daylight-friendly design of shophouse for Lhokseumawe, which it contributed to the immediate save of energy. Method used was a computer simulation utilizing Rhinoceros, Grasshopper, Ladybug and Honeybee. Climate based daylight modeling (CBDM) with Useful Daylight Illuminance (UDI) metric was adopted as a proving ground for a daylight optimization specifically for Lhokseumawe. The UDI metric utilized were for several reasons, firstly, the metric used meteorogical data for a certain location for the daylight simulation, thus, it represented a more accurate result for a specific geographical location of the study. Secondly, the metric made categorization for dissatisfactory of low daylight availability which was less than 100 Lux, the optimum range from 100 to 2000 Lux and excessive daylighting availability which falled above 2000 Lux. Obviously, this supported a better analysis result compare to a Daylight Autonomy (DA) which utilized the minimum limit of the daylight for evaluation. Among design strategies that implemented for a daylight-friendly design were building mass substraction, efficient space organization, enlarged window wall ratio (WWR), double skin and shading devices. Result showed daylight optimization was improved from 22 percents, in an existing shophouse, to 73 percents annually with the proposal from this study.
\end{abstract}

Keywords: Daylighting; Useful Daylight Illuminance (UDI); Shophouse, Rhinoceros \& Grasshoppe; Ladybug \& Honeybee.

\footnotetext{
${ }^{1}$ Program Studi Arsitektur Universitas Malikussaleh

${ }^{2}$ Program Studi Arsitektur Universitas Malikussaleh

${ }^{3}$ Jurusan Teknik Elektro Universitas Malikussaleh
} 
Atthaillah *, Amril Bakhtiar, Badriana Badriana

\section{PENDAHULUAN}

Pencahayaan alami adalah faktor yang perlu untuk selalu diperhitungkan dalam dunia arsitektur, hal tersebut disebabkan pengaruh terhadap konsumsi energi yang digunakan pada bangunan, jika energi buatan lebih banyak digunakan, maka akibatnya adalah biaya operasional mahal. Lechner (2007)menyatakan bahwa, optimalisasi pencahayaan alami dapat menurunkan konsumsi energi buatan dan biaya operasional dapat di hemat secara signifikan, sehingga beban ekonomi masyarakat dapat terbantu. Dalam upaya untuk mengoptimalkan pencahayaan alami pada bangunan, perlu untuk melihat fenomena bangunan yang sedang diminati masyarakat, agar manfaat dari upaya mengoptimalkan cahaya alami pada bangunan dapat dirasakan lebih luas. Namun hadirnya Ruko dengan desain konvensional belum dapat memberikan bukaan yang cukup, sehingga mengakibatkan bagian dalam Ruko menjadi gelap dan tidak nyaman (Andarini et al. 2009). Oleh sebab itu, perlu untuk dihadirkan desain yang dapat menyelesaikan masalah pencahayaan alami pada Ruko, agar bangunan Ruko menjadi hemat energi dan biaya operasional lebih murah.

Munculnya masalah pencahayaan alami tersebut, dapat disebabkan oleh desain Ruko yang berderet. Secara spesifik, hadirnya Ruko dengan penyatuan dinding (berderet) merupakan cara untuk mengoptimalkan pemakaian lahan (Sugiharto 2017). Ini adalah alasan mengapa bangunan Ruko berderet, bahkan dapat berderet lebih dari sepuluh Ruko. Penyatuan ini akan membatasi jumlah bukaan yang dapat digunakan karena tidak mungkin meletakkan bukaan pada dinding yang menyatu, sehingga mengakibatkan pencahayaan alami pada bangunan Ruko tidak optimal. Terlebih lagi jika terdapat lebih dari satu lantai, maka penerapan bukaan pada atap juga sulit memberi pencahayaan alami yang optimal keseluruh lantai, khususnya pada lantai pertama Ruko. Hal tersebut adalah alasan mengapa pemakaian cahaya buatan pada Ruko siang dan malam secara terus-menerus, sehingga pemborosan energi dan biaya operasional tidak dapat dihindarkan. Namun faktanya, dengan sifat boros yang terdapat pada bangunan Ruko, tetap tidak mengurangi minat masyarakat untuk membangun Ruko hingga saat ini.

Alasan tingginya minat masyarakat pada Ruko adalah nilai efektif, efisien, dan praktis yang dimiliki bangunan Ruko konvensional. Salah satu contohnya ialah fungsi ganda, yaitu sebagai tempat usaha dan tempat tinggal. Sehingga pemilik Ruko tidak perlu untuk membangun dua bangunan secara terpisah dan menghemat biaya transportasi apabila tempat usaha dan tempat tinggal dibangun terpisah. Dengan fungsi tersebut, dapat dikatakan bahwa Ruko memiliki keberlanjutan ekonomi yang sangat baik, dan akan menguntungkan jika terus dipertahankan. Tetapi jika di lihat dari kurangnya pemakaian pencahayaan alami, keuntungan tersebut bertolak belakang dengan sifat boros Ruko yang dapat merugikan pengguna. Hal tersebut adalah tantangan yang perlu untuk dijawab, yaitu bagaimana menghadirkan Ruko yang lebih hemat agar sepenuhnya dapat menguntungkan masyarakat.

Untuk menghadirkan Ruko yang lebih hemat, salah satu strategi yang dapat dilakukan adalah dengan mewujudkan desain yang dapat mengoptimalkan pencahayaan alami pada siang hari, sehingga pencahayaan alami akan mengurangi konsumsi energi yang digunakan (Lechner 2007). Dalam proses mewujudkan desain tersebut, akan dilakukan eksplorasi desain dan simulasi pencahayaan alami sebagai salah satu langkah penting. Pada proses simulasi tersebut akan memperlihatkan kualitas cahaya alami yang didistribusikan ke dalam bangunan, telah atau belum optimal.

Pada proses simulasi juga membutuhkan sebuah teknik pengukuran yang ikut mendukung tingkat akurasi hasil, teknik pengukuran yang biasa digunakan oleh perencana adalah Daylight Factor (DF), namun DF hanya dapat melakukan simulasi dengan cahaya langit dan tidak terpengaruh oleh iklim ataupun dimana bangunan tersebut berada(Nabil and Mardaljevic 2005). Lebih jauh Anderson (2014)dan Erlendsson (2014)mengatakan DF tidak mempertimbangkan 
orientasi sehingga hal ini mempengaruhi ketepatan hasil simulasi.Sementara, Daylight Autonomy (DA) yang telah menggunakan data meteorologi lokasi tertentu untuk evaluasi pencahayaan alami, namun, DA hanya menentukan batas illuminasi bawah saja untuk kategori memenuhi. Sedangkan untuk batas illuminasi atas tidak ditetapkan, hal ini tentunya akan memberikan informasi tentang ketidak-nyamanan termal akibat panas dari cahaya yang berlebih dan ketidak-nyamanan visual seperti silau tidak dapat di prediksi (Moreno and Labarca 2015). Selain itu,terdapat teknik pengukuran baru yang dinilai memiliki tingkat akurasi terbaik saat ini, yaitu Useful Daylight Illuminance (UDI). Teknik pengukuran ini dapat menggunakan kondisi geografis sesuai standar data meteorologi wilayah yang dijadikan fokus penelitian, serta hasil yang diperoleh dapat sesuai jam, tanggal, bulan ataupun setahun penuh(Nabil and Mardaljevic 2005). Terdapat pula standar optimal pencahayaan alami yang memudahkan dalam proses simulasi, jika hasil simulasi sudah dalam batas tersebut, maka pencahayaan alami yang didapatkan sudah dalam kategori optimal. Kemampuan UDI tersebut merupakan hal yang ingin dimanfaatkan pada eksplorasi desain Ruko, agar hasil yang didapatkan sesuai dan akurat, untuk melihat tingkat keberhasilan dalam mengoptimalkan pencahayaan alami yang dilakukan.

Berdasarkan latar belakang diatas, peneliti memiliki gagasan untuk melakukan penelitian dan eksplorasi desain. Hasil dari penelitian yang dilakukan ialah menghadirkan desain Ruko dengan pencahayaan alami optimal, sehingga dapat mengurangi konsumsi energi listrik dan biaya operasional dapat menjadi lebih murah.

\section{USEFUL DAYLIGHT ILLUMINANCE (UDI)}

UDI merupakan teknik pengukuran yang memiliki nilai iluminasi cahaya alami sepanjang tahun, dengan kemampuan prediksi dibawah kondisi langit sesungguhnya berdasarkan data meteorologi (Nabil and Mardaljevic 2005).Pemanfaatan pencahayaan alami merupakan langkah efektif untuk mengurangi penggunaan cahaya buatan dan energi pada bangunan, bahkan isu mengurangi penggunaan energi bangunan sudah ada sejak krisis energi pada tahun 1973. Pengendalian terhadap konsumsi energi dan cahaya buatan pada bangunan telah semakin diperhitungkan, dan teknologi-teknologi baru untuk mendukung pengendalian tersebut juga semakin dikembangkan(Fernández, Rangel, and Expósito 2014). Perkembangan teknologi tersebut tak terlepas juga pada teknik pengukuran yang digunakan pada simulasi pencahayaan alami, karena bermanfaat bagi para perancang yang membutuhkan performa simulasi lebih baik dan mendukung ketepatan hasil rancangan. Hingga kemunculan UDI merupakan sebuah kemajuan dalam simulasi komputer, kemampuan UDI sebagai teknik pengukuran baru memungkinkan perencana untuk mendapatkan kondisi cahaya alami sesuai dengan sumber yang realistis.

Selain kemudahan dalam hal tingkat akurasi yang baik, UDI juga mempermudah perencana dengan batas-batas pada hasil simulasi yang sudah ditetapkan. Batas-batas tersebut disesuaikan dengan kondisi yang akan didapatkan, apakah pencahayaan alami akan kurang (gelap), optimal atau bahkan berlebihan (silau dan panas). Berikut adalah batas-batas Daylight Illuminances yang ditetapkan dalam UDI:

Table 1. Batas-Batas iluminasi pada UDI

\begin{tabular}{ll}
\hline Illuminance (Lux) & Kategori \\
\hline$<100$ & Tidak cukup, kondisi gelap \\
\hline $100-2000$ & Optimal, kondisi iluminansi ideal \\
\hline$>2000$ & Berlebih, bisa menyebabkan silau dan panas berlebih \\
\hline
\end{tabular}

Sumber: Nabil and Mardaljevic (2005) 
Kategori illuminansi ideal ini penulis implementasikan pada studi ini karena dua alasan. Pertama, untuk Indonesia belum penulis temukan studi yang komprehensif untuk mendapatkan nilai illuminansi yang ideal untuk kawasan topis seperti Indonesia. Penulis hanya menemukan satu studi yang dilakukan oleh Mangkuto and Soelami (2014) yang mencoba menemukan korelasi antara hasil simulasi UDI dengan persepsi subjektif 17 sampel pada ruang belajar di Bandung. Studi ini menyimpulkan ada diferensiasi yang besar antara hasil simulasi UDI dengan persepsi mahasiswa. Namun, penulis tidak dapat menjadikan studi ini sebagai acuan, karena sampel yang terbatas dan data meteorologi yang digunakan bukan untuk lokasi penelitian dilakukan melainkan menggunakan data cuaca untuk Singapura. Hal ini tentunya membuat penulis tetap menggunakan UDI 100-2000 Lux yang disarankan oleh Nabil and Mardaljevic (2005) untuk kondisi optimal. Kedua, Iluminansi yang disarankan pada Standar Nasional Indonesia (SNI) yaitu SNI 03-6197 (2000) untuk berbagai ruang fungsional untuk bekerja berkisar antara 100-750 Lux. Hal ini tentunya masih dalam kriteria optimal yang diusulkan oleh metrik UDI. Sehingga untuk studi ini mengacu pada pencahayaan alami optimal seperti disarankan oleh metrik UDI.

Penelitian pencahayaan alami pada bangunan dengan karakter berderet sudah pernah dilakukan sebelumnya yaitu pada rumah tinggal tipe townhouse. Penelitian yang dilakukan di Surabaya olehDora and Nilasari (2011), bertujuan untuk mengembangkan penggunaan cahaya alami dan menghemat energi listrik. Letak bangunan yang berderet dan saling menyatu mengakibatkan ketersediaan bukaan sangat sedikit, sehingga distribusi pencahayaan alami ke dalam ruangan tidak optimal dan ketergantungan cahaya buatan mendorong kebiasaan boros energi(Dora and Nilasari 2011). Dari penelitian yang dilakukan, terdapat kesimpulan berupa cara untuk mengoptimalkan pencahayaan alami pada bangunan tipe ini. Cara pertama adalah dengan memperbesar bukaan 40 - 80 persen dari luas dinding, kedua dengan menambahkan Skylight dan cara ketiga adalah dengan menggunakan Louvre dan kanopi. Gabungan dari ketiga cara tersebut akan menambah intensitas cahaya alami didalam ruangan, mendistribusikan keseluruh ruangan secara merata serta lebih terkendali dari silau dan panas. Dengan demikian, pencahayaan alami dapat dimanfaatkan secara lebih baik, sehat dan hemat pada rumah tinggal tipe townhouse di Surabaya.

Teknik UDI juga dapat digunakan sebagai cara untuk mencari solusi dari kondisi cahaya alami yang berlebihan. Abu-Dakka (2009) melakukan penelitian terhadapat pencahayaan alami yang berlebihan, dengan tujuan agar menemukan solusi terbaik yang dapat digunakan. Penelitian ini dilakukan pada gedung perkantoran, dengan tantangan karekteristik radiasi matahari seharihari Dubai yang tinggi. Salah satu percobaan dilakukan pada sisi barat gedung dengan silau dan panas berlebih menjadi masalah yang biasa muncul pada sisi ini, serta tingkat kesulitan untuk mengoptimalkan pencahayaan alami lebih tinggi. Dari tantangan tersebut, peneliti mencoba melakukan tindakan eksplorasi dengan menambahkan irisan plat pada bukaan dan memasang kaca visible transmittance (VT). Hasil simulasi dengan UDI memperlihatkan nilai lux yang sebelumnya 5000 lux dapat diturunkan sebesar 70 persen menjadi 150 lux, dengan hasil tersebut dapat dikatakan bahwa percobaan dengan UDI dapat memberikan kondisi pencahayaan alami ke dalam batas optimal.

Percobaan untuk membedakan performa teknik pengukuran dan pemanfaatan pencahayaan alami sebagai penghemat konsumsi energi pada gedung perkantoran. Fernández, Rangel, and Expósito (2014) melakukan penelitian tersebut dengan menggunakan tiga teknik berbeda yaitu DF, Daylight Autonomy (DA) dan UDI. Percobaan tersebut dilakukan terlebih dahulu pada sebuah geometri sederhana dengan dimensi $3 \times 3 \times 3$ meter, dan menambahkan jendela dengan lebar $0.95 \times 0.95$ meter. Hasilnya adalah, teknik UDI dengan data cuaca atau meteorologi memberikan informasi yang lebih baik dalam hal kuantitas cahaya alami yang masuk kedalam ruangan (Fernández, Rangel, and Expósito 2014). Jika dibandingkan dengan DF dan DA, UDI lebih membantu dalam proses desain dan rencana pencahayaan. Hasil dari percobaan diatas kemudian 
diaplikasikan ke gedung perkantoran dengan menambahkan alat sensor otomatis (automatically switch off the lighting system), agar lampu secara otomatis mati jika cahaya alami cukup. Dengan demikian, konsumsi energi untuk pencahayaan yang sebelumnya sebesar $31.9 \mathrm{kWh} / \mathrm{m}^{2}$ pertahun, dapat berkurang menjadi $13.3 \mathrm{kWh} / \mathrm{m}^{2}$ pertahun. Dari pencapaian tersebut dapat disimpulkan bahwa konsumsi energi untuk pencahayaan berhasil dihemat sebesar 50 persen pertahun. Pencapaian tersebut memperlihatkan performa UDI sangat informatif dalam mendukung pencarian solusi terbaik untuk optimalisasi pencahayaan alami dan penghematan konsumsi energi.

Lebih jauh, penelitian yang memiliki banyak kesamaan dengan penelitian ini adalah penelitian yang dilakukan olehVichuda, Pipat, and Pattana (2014), kesamaan yang dimaksud ialah pada objek penelitian (bangunan komersial), teknik UDI dan iklim tropis. Penelitian tersebut mencoba untuk menghindarkan efek silau dan panas dari cahaya alami pada bangunan komersial di Thailand, dengan percobaan meningkatkan kualitias pencahayaan alami dari bukaan sisi bangunan. Simulasi yang dilakukan pada penelitian ini berdasarkan data cuaca Thailand, yang masuk dalam wilayah beriklim tropis. Hasil simulasi menunjukkan bahwa, ketika irisan papan pada bagian bawah dan bagian atas bukaan dimiringkan dengan sudut yang tepat, maka bukaan pada kedua sisi dapat meningkatkan kualitas pencahayaan alami ke dalam ruangan lebih optimal. Hal tersebut juga dapat mengakibatkan distribusi pencahayaan alami ke dalam ruangan lebih merata. Hasil dari percobaan dapat digunakan pada seluruh bukaan yang ada, dengan penghematan yang dapat dicapai adalah sekitar 31 persen dari energi listrik untuk penerangan, dan sekitar 26 persen dari total energi listrik bangunan tersebut. Pada penelitian tersebut memperlihatkan bahwa, jika cahaya alami iklim tropis yang berlimpah dapat dioptimalkan sehingga dapat terhindar dari silau dan panas, maka konsikuensinya adalah energi listrik akan lebih hemat.

Dari penelitian tersebut maka terdapat dua perbedaan dengan apa yang dilakukan pada studi ini. Pertama, belum terdapat penelitian yang mencoba mengoptimalkan pencahayaan alami dengan teknik UDI pada bangunan Ruko di Indonesia, khususnya di Kota Lhokseumawe. Kedua, tidak terdapat penelitian yang memberikan proposal desain Ruko secara komplit, ditambah dengan pencahayaan alami sudah optimal pada desain tersebut.

\section{METODE}

Metode penelitian yang digunakan adalah studi simulasi komputer.Groat and Wang (2013) menjelaskan bahwa simulasi komputer merupakan representasi dari suatu tingkah laku maupun karakterisktik dengan menggunakan suatu sistem yaitu program komputer. Dalam hal ini penulis mengoptimalkan pencahayaan alami dalam desain arsitektur. Simulasi pencahayaan alami merupakan sebuah proses mewujudkan desain arsitektur sadar lingkungan, proses tersebut sudah ada sejak 50 tahun yang lalu dan terus berkembang hingga kini sebagai metode simulasi komputer.

Perkembangan simulasi pencahayaan alami terletak pada metode simulasi yang digunakan, dengan tujuan agar dapat mendukung hasil yang lebih akurat. Sejak pertama kali dikenalkan, metode simulasi pencahayaan alami masih bersifat statis. Metode yang bersifat statis merupakan metode yang menggunakan sumber cahaya hanya pada satu kondisi langit saja dan tidak memperhitungkan perbedaan cuaca suatu wilayah, bahkan berbagai kondisi pencahayaan alami pada negara yang berbeda atau benua yang berbeda akan dianggap sama. Sehingga dari keterbatasan yang dimiliki, hasil yang didapatkan dinilai kurang akurat (Nabil and Mardaljevic 2005). Perkembangan metode simulasi saat ini telah sampai pada metode yang bersifat dinamis. Metode tersebut dapat memberikan referensi pencahayaan alami sesuai dengan perbedaan kondisi iklim, cuaca, lokasi dan waktu selama setahun penuh. Data meteorologi merupakan sumber 
Atthaillah *, Amril Bakhtiar, Badriana Badriana

referensi pencahayaan alami pada saat simulasi dilakukan, dengan demikian akan didapatkan hasil yang lebih akurat dan responsif terhadap kondisi langit pada wilayah, negara ataupun benua yang berbeda-beda.

Sebagaimana ditegaskan oleh Matterson et al. (2013), bahwa kemampuan teknik pengukuran bersifat dinamis dibutuhkan untuk melakukan analisis terhadap kondisi langit yang berbedabeda.Teknik-teknik yang dapat melakukan simulasi dinamis ialah Daylight Autonomy (DA) dan Useful Daylight Illuminance (UDI). Namun dari kedua teknik simulasi tersebut, UDI merupakan teknik yang lebih komplit dan terbaru. Teknik UDI dapat menampilkan persentase jika hasil simulasi di bawah batas minimum (gelap), dan jika hasil simulasi melebihi batas maksimum atau silau (Anderson 2014). Kemampuan merepresentasikan batas minimum dan maksimum tersebut adalah hal yang tidak dapat dilakukan oleh DA, sehingga UDI dinilai lebih akurat dan efektif. Kelebihan yang dimiliki UDI merupakan alasan peneliti memilih UDI sebagai metode simulasi dalam penelitian ini, teknik UDI tersebut dijalankan dalam plugin Grasshopper dan LadybugHoneybee yang telah diintegrasikan dengan Program Rhinoceros.

Rhinoceros merupakan piranti permodelan yang berbasis Non-Uniform, Rational B-spline Surface (NURBS) yang di buat oleh Robert McNeel \& Ascociates. Sementara, Grasshopper merupakan sebuah plugin Rhinoceros yang berupa antar muka pemrograman visual, node-based, yang pertama sekali diperkenalkan oleh David Rutten pada 2007 dengan nama Explicit History dan diberi nama ulang menjadi Grasshopper pada tahun 2008 (Tedeschi 2014). Ladybug \& Honeybee, sebuah plugin Grasshopper,yang merupakan piranti analisis lingkungan seperti analisis pencahayaan alami, kenyamanan termal, dan analisis energi yang dapat terhubung dengan engine simulasi yang tervalidasi seperti EnergyPlus, Radiance, Daysim dan OpenStudio (Roudsari and Pak 2013).

Langkah awal yang kami lakukan adalah pengumpulan data. Hal ini dilakukan dengan survey lapangan dan pengukuran bangunan Ruko terhadap beberapa Ruko yang dapat mewakili kondisi Lhokseumawe. Kemudian data lapangan ini kami gunakan untuk permodelan digital dengan Rhinoceros. Kemudian data tersebut dimodelkan di Rhinoceros. Selanjutnya, data permodelan diinput kedalam Grasshopper. Terakhir, data yang sudah diinput kemudian dihubungkan dengan komponen Ladybug-Honeybee pada bagian persiapan model untuk melakukan simulasi dan mendapatkan hasilnya. Untuk simulasi ini kami menggunakan file cuaca berformat .epw (EnergyPlus Weather) untuk Kota Lhokseumawe. Gambar 1 menjelaskan alur kerja algortima yang kami gunakan pada studi ini.

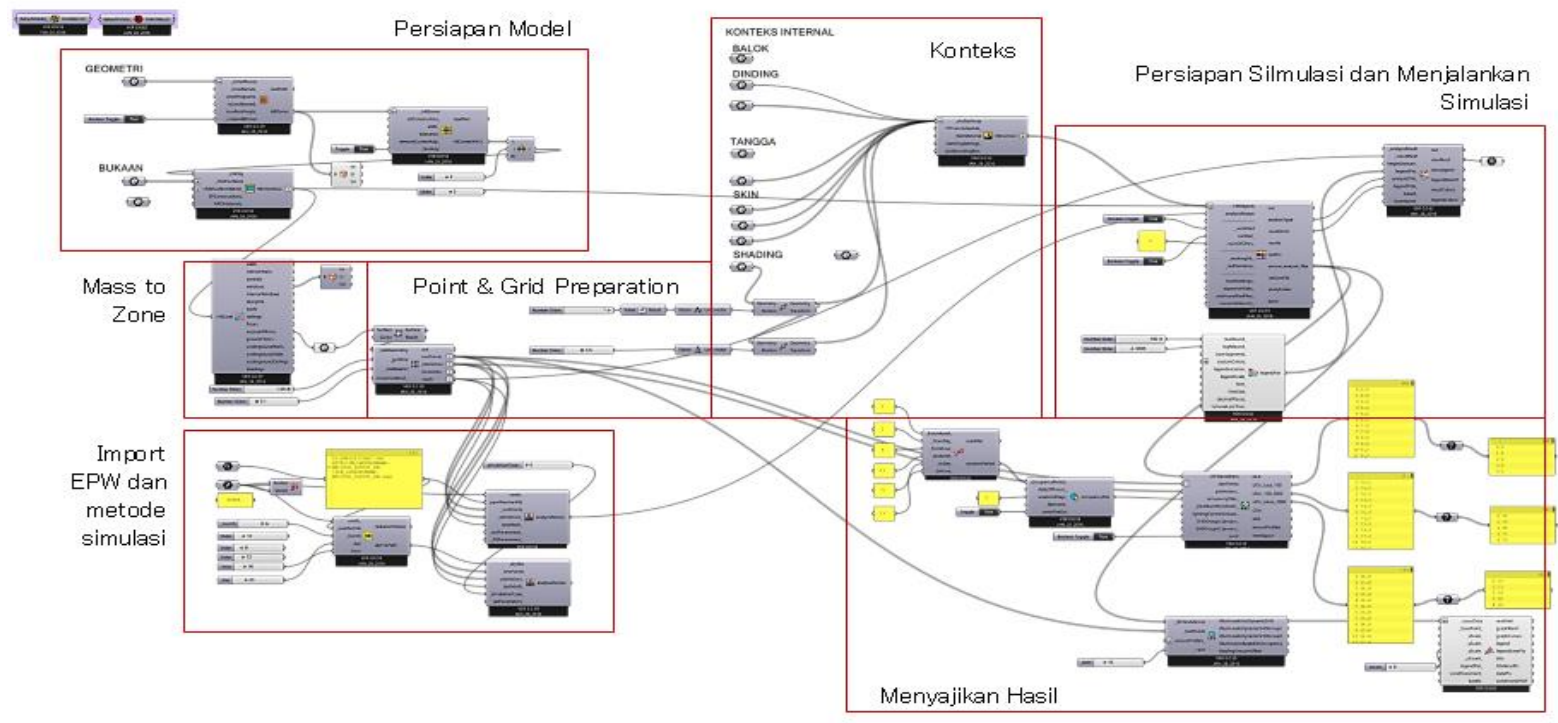

Gambar 1. Algoritma Grasshopper untuk simulasi UDI pada penelitian ini Sumber: Olah Data (2019) 
Objek Ruko yang menjadi referensi permodelan pada studi ini ditunjukkan pada Gambar 2. Pada gambar tersebut kami mengambil Ruko yang memiliki 3 (tiga) lantai. Hal ini disebabkan tren bangunan Ruko di Lhokseumawe mengarah kepada banguna berlantai 3 (tiga). Hanya Ruko lama saja yang berlantai 2 (dua). Selain itu, pemasalahan pencahayaan alami pada bangunan tiga lantai ini penulis temukan bermasalah dengan luasan yang lebih besar. Kesumua objek penelitian tersebut terletak di pusat Kota Lhokseumawe.

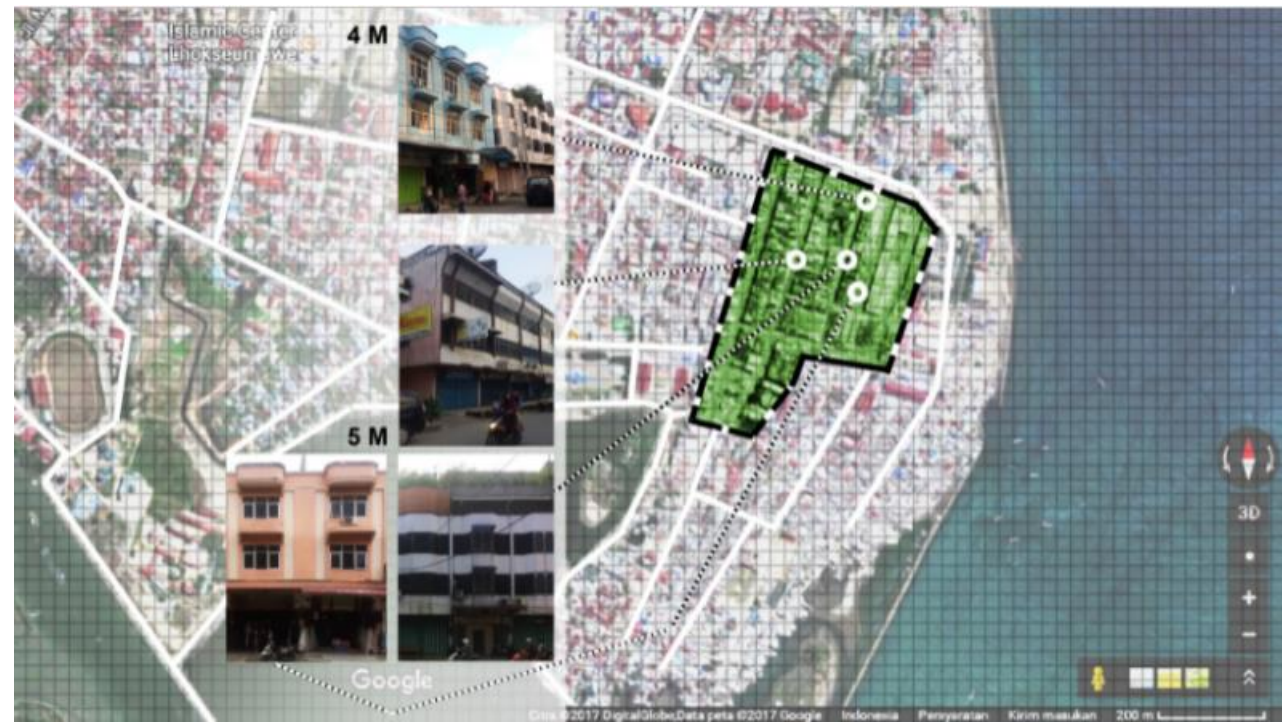

Gambar 2. Objek penelitian sebagai referensi permodelan, atas memiliki lebar 4m (atas) dan 5m

(bawah)

Sumber: Olah Data (2019)

Ruko yang menjadi objek pada penelitian ini memiliki lebar 5 meter dan panjang 23 meter (kiri bawah pada Gambar 2), terdiri dari tiga lantai dengan tinggi tiap lantainya adalah 3.5 meter. Pemilihan objek penelitian dengan lebar 5 meter, berdasarkan dari persentase jumlah Ruko dengan lebar 5 meter di lokasi penelitian mencapai 80 persen. Ruko yang menjadi objek penelitian memiliki kondisi dinding kiri dan kanan menyatu langsung dengan Ruko disebelahnya dan membentang dari Timur Laut ke Barat Daya, penyatuan dinding tersebut memberikan keuntungan dari masalah keterbatasan lahan dan mahalnya harga tanah di perkotaan. Material yang digunakan merupakan jenis-jenis material yang biasa terdapat pada Ruko konvensional, yaitu bata merah, semen, keramik dan kaca. Data berupa ukuran luas dan jumlah lantai tetap digunakan sebagai acuan. Fungsi dari ketiga lantai pada Ruko yang menjadi sampel adalah, pertama, sebagai tempat usaha. Kedua, sebagai tempat usaha dan gudang. Lantai tiga pada objek yang menjadi acuan masih belum digunakan.

Adapun luas keseluruhan adalah $347 \mathrm{~m}^{2}$ dengan kondisi denah seperti ditunjukkan pada Gambar 3. Bukaan pada Ruko yang menjadi acuan hanya terdapat pada bagian depan dan belakang bangunan. Hal ini disebabkan kondisi Ruko yang berdempetan langsung. Kondisi window wall ratio (WWR) pada lantai satu sebeasar $8.47 \%$, lantai dua dan tiga masing-masing 3.31\%. 
Atthaillah *, Amril Bakhtiar, Badriana Badriana

\section{HASIL DAN PEMBAHASAN}

Simulasi pada desain eksisting bertujuan untuk mengetahui persentase pencahayaan alami pertahun, serta akan menjadi perbandingan dengan desain proposal. Model tiga dimensi (3D) dalam simulasi mengikuti kondisi eksisiting yang didapatkan dari hasil survei pada objek penelitian, tanpa merubah apapun pada ukuran panjang, lebar, tinggi, kontruksi, bukaan, orientasi maupun konteks. Hasil simulasi kondisi eksiting terlihat seperti pada Gambar 4.

Dari hasil tersebut dapat digambarkan bahwa distribusi pencahayaan alami pada setiap lantai didominasi gelap yaitu sebesar 76 persen pertahun, dan persentase optimal hanya sebesar 22 persen pertahun dan kondisi panas dan silau 2 persen. Kesimpulannya adalah, pencahayaan alami pada desain eksisting atau objek penelitian belum optimal, hal tersebut diakibatkan oleh persentase gelap yang masih terlalu besar. Dari kondisi pencahayaan alami yang belum optimal tersebut, maka kami mengusulkan proposal desain Ruko yang optimal terhadap pencahayaan alami dengan metrik UDI. Ada beberapa strategi yang kami implementasikan untuk mecapai kondisi optimal pencahayaan alami pada proposal yang kami ajukan yaitu modifikasi gubahan massa, optimalisasi window wall ratio (WWR) dengan desain bukaan, daylight shaft dan skylight, selubung ganda dan shading devices.Sebagian strategi tersebut merupakan hasil kombinasi dan alterasi yang disarankan dari penelitian sebelumnya yaitu Dora and Nilasari (2011), Abu-Dakka (2009), Fernández, Rangel, and Expósito (2014) serta Vichuda, Pipat, and Pattana (2014).

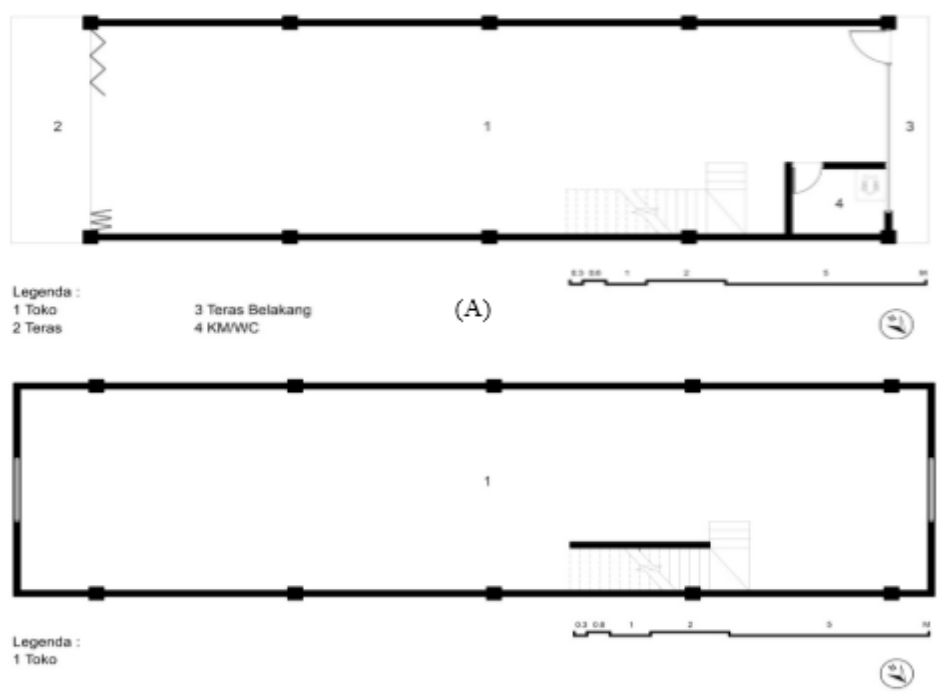

(B)

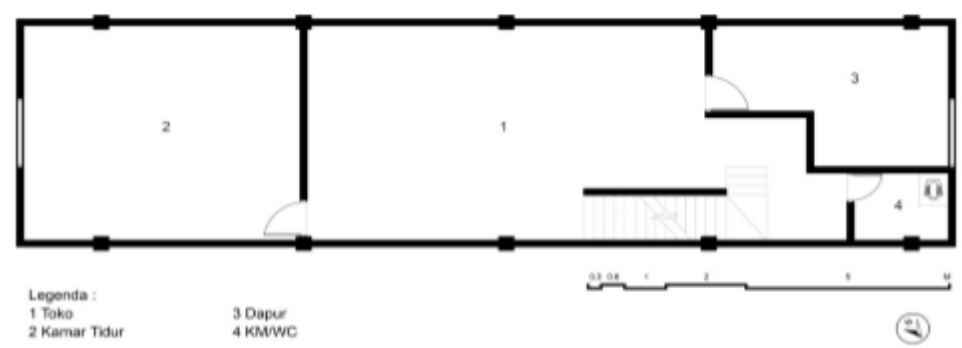

(C)

Gambar 3. Denah Ruko yang menjadi acuan permodelan Sumber: Hasil Analisis (2019) 


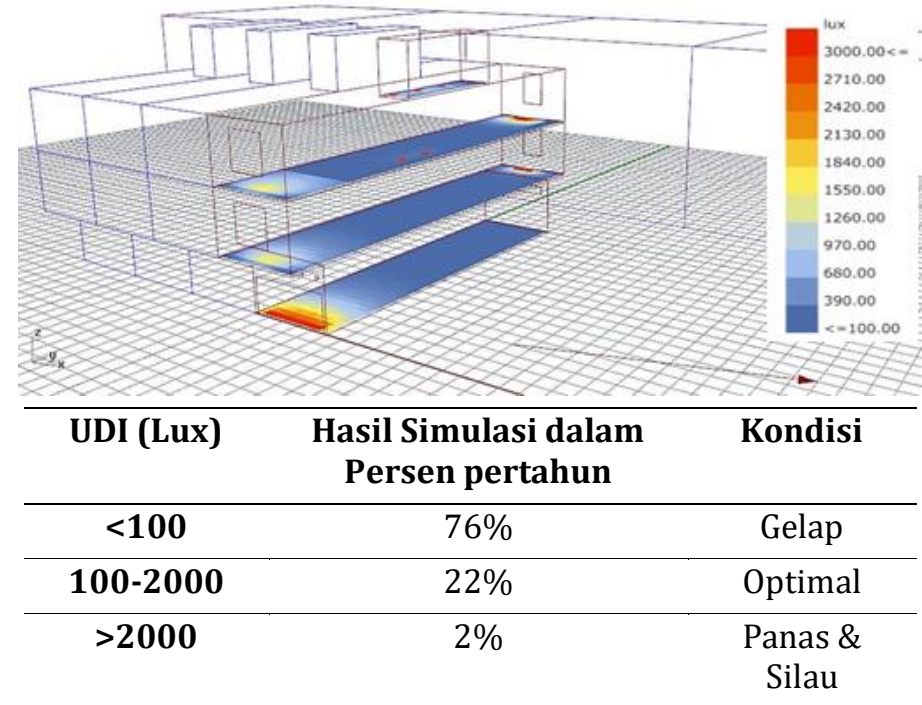

Gambar 4. Climate-based simulation pada 22 Juni (atas), hasil simulasi UDI (bawah) Sumber: Hasil Analisis (2019)

Modifikasimassabangunan kami lakukan untuk mendapatkan posisi bukaan yang lebih banyak. Untuk itu kami melakukan proses subtraksi pada beberapa bagian yang kami analisis memiliki potensi mendapatkan pencahayaan yang lebih baik. Substraksi massa yang paling penting adalah pada bangunan tengah bangunan, hal ini dapat memasukkan cahaya pada area yang tidak terjangkau pada kondisi eksisting. Prinsip substraksi bangunan yang kami lakukan ditunjukkan pada Gambar 5. Proses substraksi ini menyebabkan perubahan pada bentuk denah Ruko. Selain itu, kondisi perubahan juga memungkinkan nilai WWR bisa ditingkatkan.
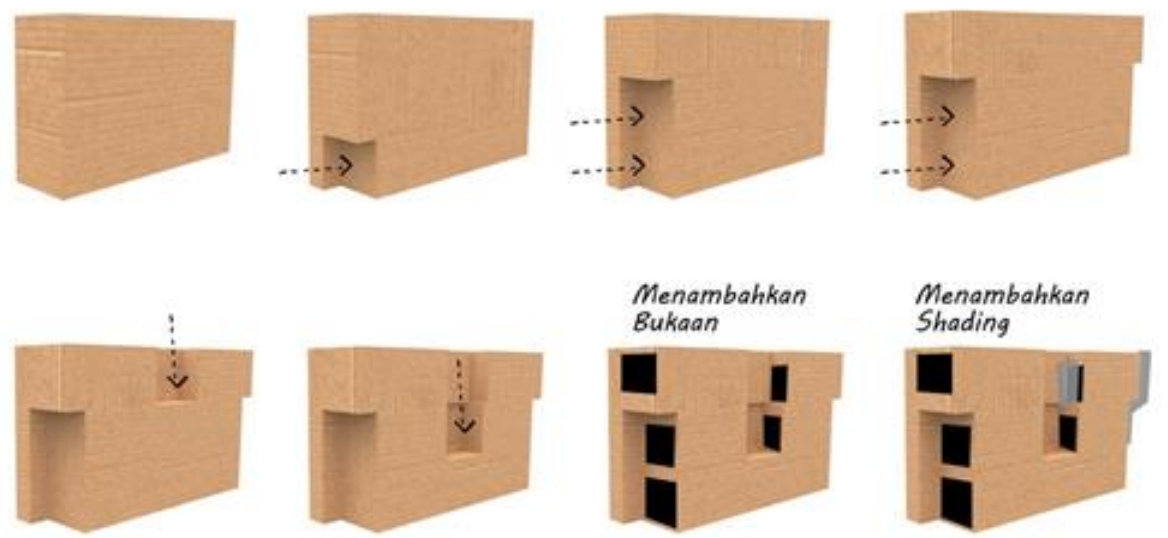

Gambar 5. Prinsip subtraksi Ruko untuk pencahayaan alami yang lebih optimal Sumber: Hasil Analisis (2019)

Terkait dengan WWR, pada desain eksisting Ruko, lantai pertama 8.47\%, lantai dua dan tiga masing-masing 3.31\%. Kondisi ini tentunya menggambarkan kondisi ruang yang mayoritas gelap. Hasil simulasi pada gambar 4 diatas juga telah menunjukkan hasil ruangan yang mayoritas gelap yaitu 76\% dengan metrik UDI. Dari hasil modifikasi massa bangunan diatas maka nilai WWR ini berhasil kami tingkatkan, lantai satu 14.64\%, lantai dua 19.69 dan lantai tiga $10.76 \%$. Kondisi WWR ini masih rendah dari yang seharusnya 30\% walau sudah memaksimalkan bidang dinding hasil modifikasi gubahan massa. Namun, Ruko proposal membuat daylight shaft dan skylight pada 
Atthaillah *, Amril Bakhtiar, Badriana Badriana

bagian tengah bangunan. Hal ini berperan sangat signifikan untuk meningkatkan kualitas pencahayaan alami pada bangunan.

Hal ini tentunya membawa perubahan luasan dan denah bangunan. Kondisi eksisting untuk 3 lantai memiliki luas $347 \mathrm{~m} 2$. Sementara pada proposal ini luas bangunan menjadi $296 \mathrm{~m} 2$. Pengurangan luas bangunan yang signifikan ini diakibatkan oleh perpotongan yang dilakukan untuk dapat mendapatkan cahaya alami yang optimal kedalam bangunan. Pada studi ini kami menawarkan organisasi ruang yang optimal sesuai dengan fungsi Ruko yaitu tempat tinggal dan tempat berdagang. Fungsi privat sebagai tempat tinggal kami letakkan di lantai tiga, sedangkan, fungsi berdagang kami letakkan di lantai satu dan dua. Dengan organisasi ruang yang kami tawarkan mengacu pada prinsip tidak mengurangi kenyamanan untuk tinggal sekaligus dapat dilakukan untuk berdagang secara nyaman pula walau ada porsi lantai yang dihilangkan untuk light shaft. Hal ini meningkatkan kualitas psikologis dan kesehatan penghuni Ruko dengan mendapatkan pencahyaan yang alami. Sehingga hal ini menjadi nilai tawar untuk penjualan Ruko. Adapun denah proposal yang kami maksud dapat lihat pada gambar 6.

Selanjutnya, penambahan selubung ganda dan shading devices. Kulit ganda ini berfungsi, pertama, untuk meminimalisir kondisi cahaya alami berlebih yang masuk kedalam bangunan (Dewi, Huang, and Nugroho 2013). Selanjutnya, selubung ganda ini untuk meningkatkan tampilan Ruko menjadi lebih baik dengan harapan memiliki nilai jual yang lebih baik pula. Kami mencoba untuk memambahkan kanopi seperti desain Ruko pada umumnya dengan kondisi massa dan WWR seperti telah dijelaskan diatas. Namun, seperti ditunjukkan pada gambar 7, hasil simulasi menunjukkan kondisi cahaya berlebih pada ruangan Ruko. Hal ini menimbulkan kondisi panas dan potensi silau. Sehingga sebagai strategi memperbaiki kondisi ini kami menambahkan kulit ganda dan shading devices.
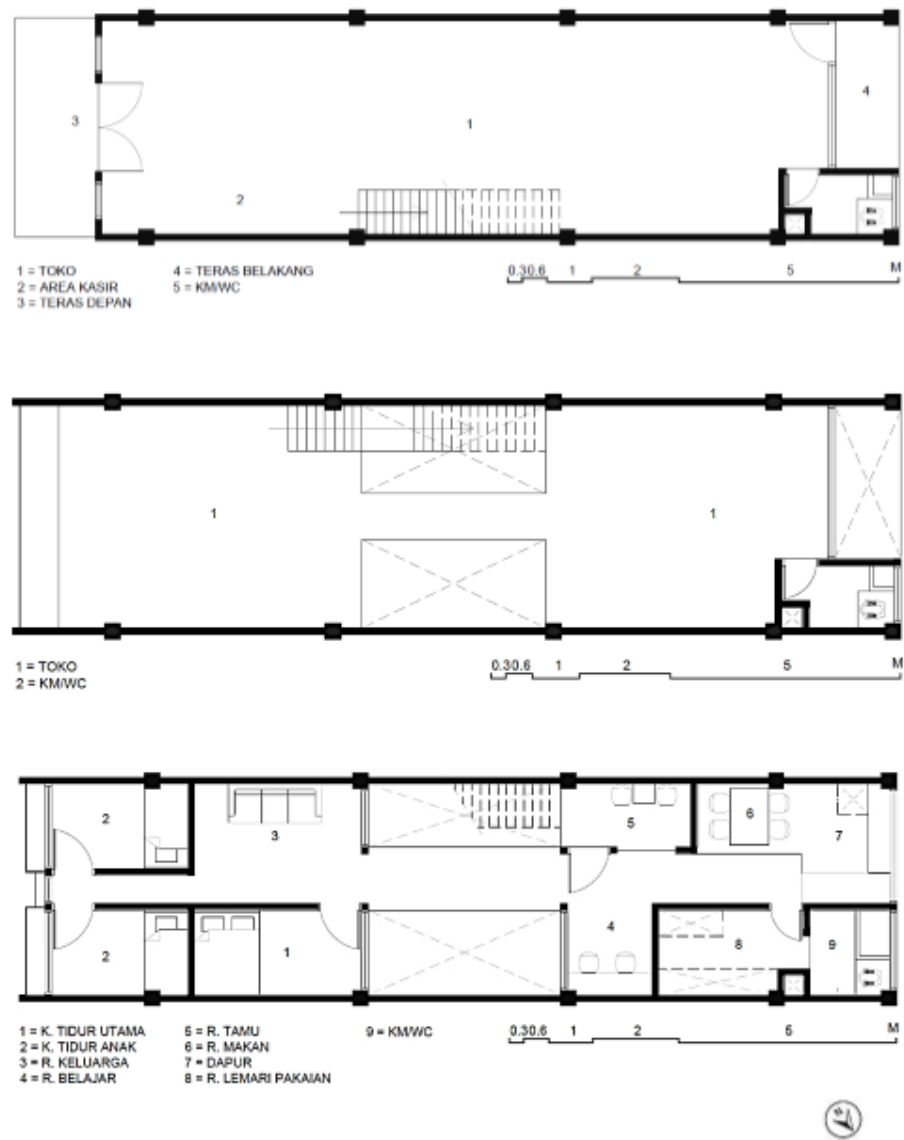

Gambar 6. Denah proposal, lantai satu (atas), lantai 2 (tengah) dan lantai tiga (bawah) Sumber: Hasil Analisis (2019) 
Kulit ganda yang kami usulkan pada studi ini adalah kulit berpori dengan bentuk segitiga dengan ukuran berbeda-beda sesuai dengan posisi dan peluang menerima cahaya berlebih. Desain kulit ganda dapat dilihat pada gambar 8.

Berikutnya, penambahan shading devices yang terletak pada skylight dan light shaft. Filter cahaya yang kami integrasikan pada skylight adalah bilah-bilah $5 \times 10 \mathrm{~cm}$ yang disusun dengan jarak $18 \mathrm{~cm}$ dengan kemiringan yang berbeda antara bilah area pertama dan bilah pada area kedua. Ilustrasi bilah area pertama dan kedua dapat dilihat pada gambar 9. Kemiringan bilah-bilah tersebut adalah 50 derajat. Hal ini memastikan cahaya alami tidak berlebihan pada lantai tiga dan sekaligus memastikannya sampai ke lantai satu. Terkait dengan kemiringan desain bilah-bilah pada light shaft dapat dilihat pada tabel 2. Alasan pemilihan bilah sirip horizontal diperkuat oleh studi yang dilakukan oleh penulis utama, bahwa sirip horizontal lebih optimal digunakan untuk pencahayaan alami pada iklim tropis khususnya Lhokseumawe sebagai fasad bangunan (Atthaillah, Wijayanti, and Hassan 2018). Untuk memastika cahaya dapat diteruskan dengan optimal ke seluruh lantai, maka, kami mendesain floating stair pada light shaft.

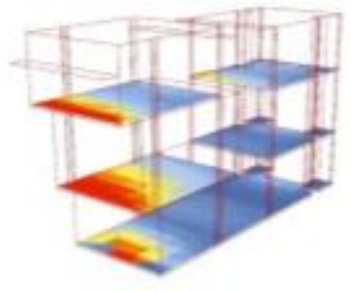

09.00 WIB

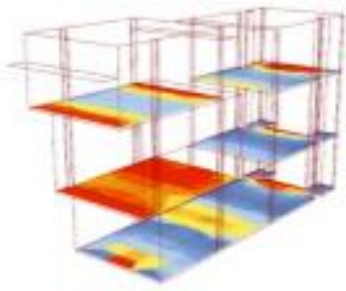

12.00 WIB

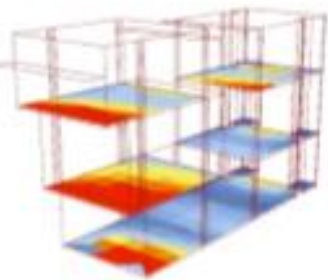

16.00 WIB

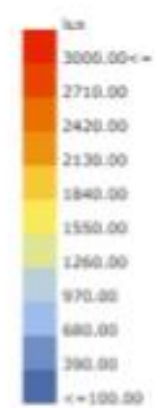

Gambar 7. Hasil simulasi overbright dengan WWR, light shaft dan penambahan kanopi Sumber: Hasil Analisis (2019)

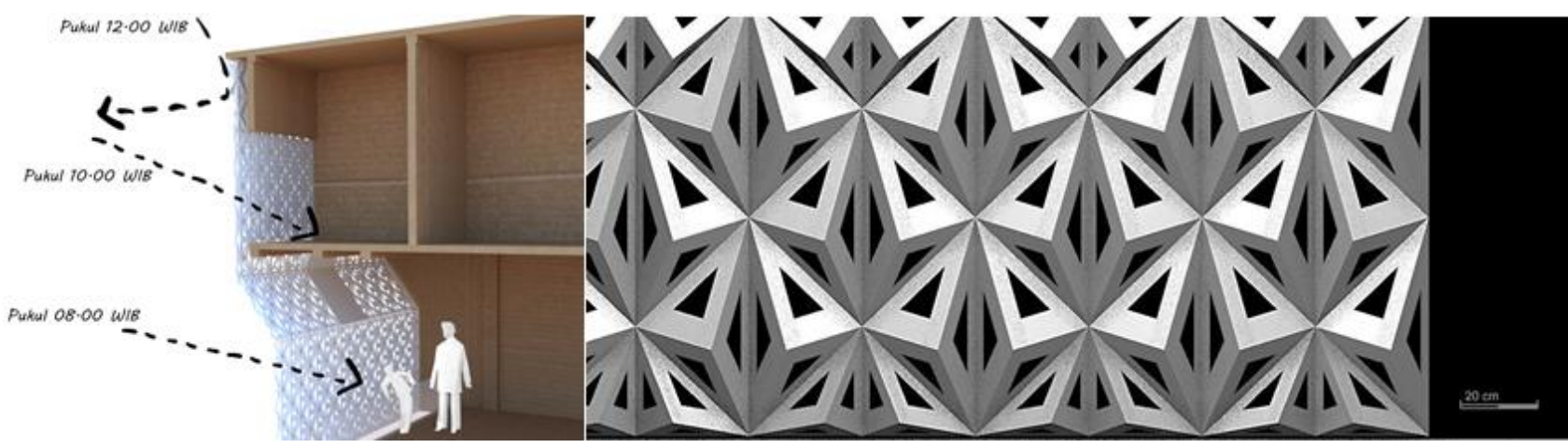

Gambar 8. Desain kulit ganda yang diletakkan pada depan Ruko (kanan) dan detail desain (kiri) Sumber: Hasil Analisis (2019) 


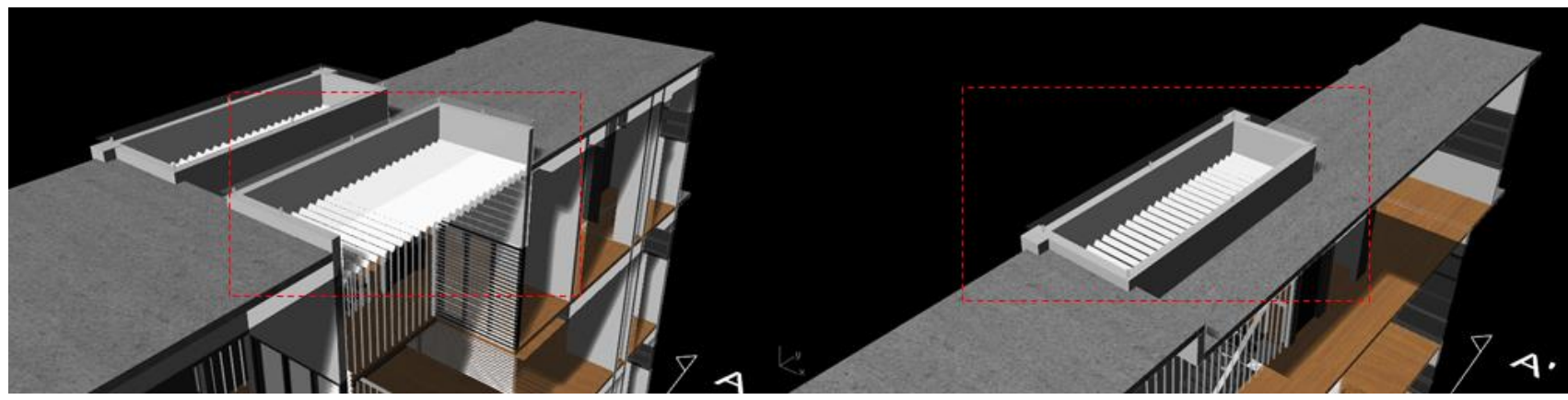

Gambar 9. Filter cahaya pada skylight, bilah area pertama (kiri) dan bilah area kedua (kanan)

Sumber: Hasil Analisis (2019)

Tabel 2. Desain dan kemiringan bilah-bilah filter cahaya pada light shaft

LOKASI
JARAK BILAH (cm)

Dengan konfigurasi seperti dijelaskan sebelumnya, penulis melakukan analisa pada tanggal dan bulan terdingin dan terpanas yaitu 21 Juni dan 21 Desember (Lechner 2007). Simulasi kami lakukan dengan mengambil tiga waktu yaitu pukul 08.00, 12.00 dan 16.00. Hal ini kami lakukan untuk melihat pola distribusi cahaya dengan strategi desain yang telah dijelaskan diatas pada 
Atthaillah*,

Amril Bakhtiar, Badriana Badriana

waktu pagi, siang dan sore hari. Hasil simulasi yang dimaksud dapat dilihat seperti pada gambar 10 dan 11.

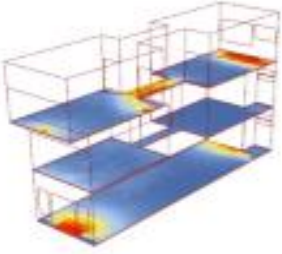

09.00 WIB

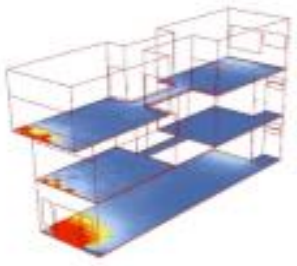

09.00 WIB

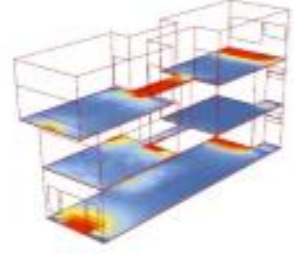

12.00 WIB

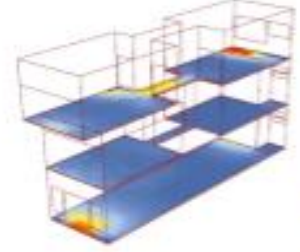

$16.00 \mathrm{WIB}$
Gambar 10. Simulasi pada 21 Juni

Sumber: Hasil Analisis (2019)

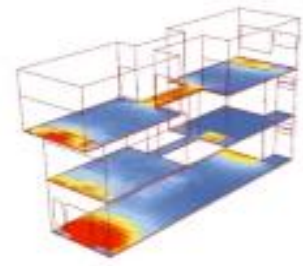

12.00 WIB

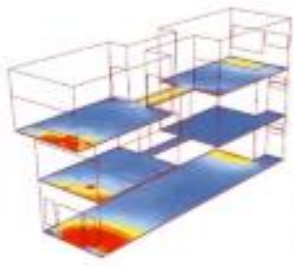

16.00 WIB
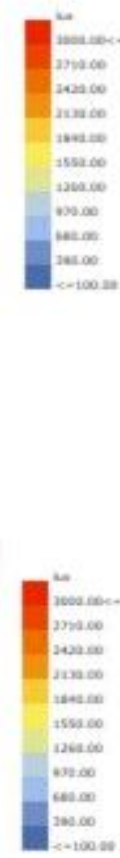

Gambar 11. Simulasi pada 21 Desember

Sumber: Hasil Analisis (2019)

Kondisi pencahayaan alami didalam bangunan sudah terlihat lebih baik dibandingkan dengan gambar 7, sebelum semua strategi desain seperti dijelaskan diterapkan. Berbekal dua tolak ukur ini, selanjutnya, kami melakukan simulasi tahunan dengan metrik UDI. Simulasi tahunan dilakukan dari 1 Januari sampai 31 Desember dari pukul 08.00 sampai pukul 16.00. Hasil simulasi tahunan dengan metrik UDI tersebut ditunjukkan pada tabel 2.

Tabel 3. Hasil simulasi proposal desain dengan metrik UDI

\begin{tabular}{ccc}
\hline UDI (Lux) & Hasil Simulasi dalam Persen pertahun & Kondisi \\
\hline$<\mathbf{1 0 0}$ & $14 \%$ & Gelap \\
\hline $\mathbf{1 0 0 - 2 0 0 0}$ & $\mathbf{7 3 \%}$ & Optimal \\
\hline$>\mathbf{2 0 0 0}$ & $13 \%$ & Panas \& Silau
\end{tabular}

Sumber: Hasil Analisis (2019)

Dari hasil persentase di atas, terlihat bahwa proposal desain dapat mengoptimalkan pencahayaan alami dengan persentase sebesar 73 persen. Sedangkan untuk persentase gelap ialah 14 persen dan untuk persentase silau ialah 13 persen. Besarnya persentase gelap diakibatkan oleh konteks pada bagian belakang Ruko seperti telihat pada gambar 4. Konteks tersebut menghalangi distribusi cahaya alami ke arah Ruko sehingga mengurangi distribusi sekitar 20 persen, walaupun sudah dilakukan upaya memaksimalkan bukaan pada bagian belakang proposal desain. Sedangkan untuk persentase silau berhasil dikurangi walaupun menggunakan bukaan yang lebar, hal tersebut 
Atthaillah *, Amril Bakhtiar, Badriana Badriana

diakibatkan keberhasilan strategi selubung ganda dan shading devices. Gambar 12 menunjukkan perbandingan nilai UDI pada desain Ruko eksisting dan proposal pada penelitian ini.

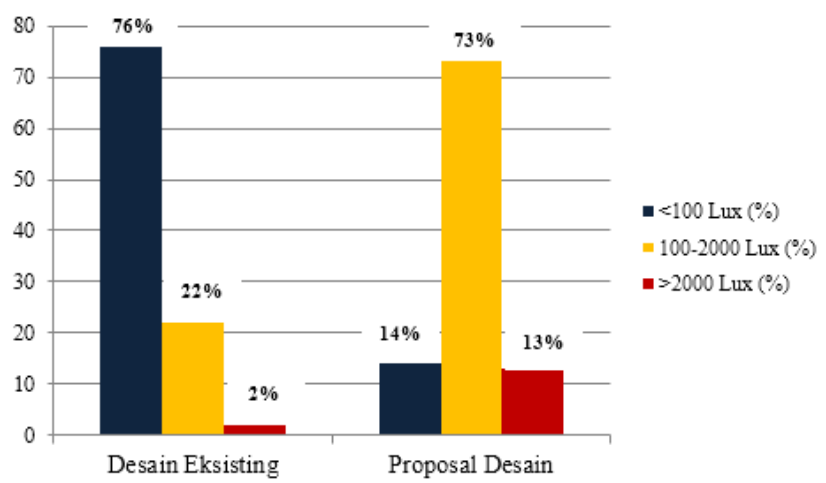

Gambar 12. Grafik perbandingan Ruko eksisting dan rencana dengan metrik UDI Sumber: Penulis (2019)

\section{KESIMPULAN}

Proposal yang diusulkan pada penelitian ini menunjukkan salah satu teknik pengoptimalan pencahayaan alami pada bangunan Ruko. Strategi-strategi yang ditawarkan merupakan hasil analisis penulis yang berorientasi pada pengoptimalan pencahayaan dengan tetap mempertimbangkan organisasi ruang bangunan yang lebih baik.Strategi substraksi bangunan juga membuka peluang untuk memperbesar nilai WWR. Hal ini disebabkan oleh area hasil substraksi memiliki bagian bidang yang dapat digunakan untuk meneruskan cahaya alami. Alterasi WWR menjadi lebih besar dan substraksi massa menjadi light shaft pada objek studi membutuhkan integrasi solusi kulit ganda dan shading devices sehingga iluminasi yang menjadi intensi pada metrik UDI, 100-2000 Lux, dapat ditingkatkan dengan signifikan. Hal ini terbukti dari hasil simulasi pada studi ini, nilai iluminasi optimal meningkat dari 22 persen menjadi 73 persen pertahun.

Terkait shading devices, yaitu sirip horizontal, penelitian ini menunjukkan untuk pencahayaan optimal memiliki kemiringan tersendiri sesuai dengan posisi/lokasi dan orientasi dari sirip horizontal seperti telah dipaparkan sebelumnya. Peran orientasi ini terlihat jelas dengan menggunakan metrik UDI hal ini tidak didapatkan pada penelitian simulasi dengan Daylight Factor (DF). Selain itu, jarak antar bilah juga berpengaruh terhadap pengoptimalan pencahayaan alami. Lebih jauh, kondisi konteks yang padat juga memiliki kontribusi krusial terhadap penerimaaan cahaya alami.

Proposal Ruko pada penelitian diharapkan berkontribusi terhadap pengurangan konsumsi energi akibat penggunaan pencahayaan buatan pada hampir semua Ruko yang ada di Lhokseumawe maupun Indonesia pada umumnya. Namun, untuk daerah lainnya diperlukan simulasi kembali untuk mendapatkan desain Ruko yang optimal terhadap pencahyaan alami dengan strategi-strategi desain yang diimplementsikan pada penelitian ini. 


\section{DAFTAR REFERENSI}

Abu-Dakka, Moana Ghazi. 2009. "The Use of Useful Daylight Illuminance (UDI) to Test New Designs for Improving Daylight Performance of Office Buildings in Dubai-UAE." The British University in Dubai. https://bspace.buid.ac.ae/bitstream/1234/115/1/60032.pdf.

Andarini, Rahmi, H Schranzhofer, W Streicher, and A K Pratiwi. 2009. "Thermal Simulation and Cooling Energy Sensitivity Analysis of a Typical Shophouse in Jakarta, Indonesia." In Eleventh International IBPSA Conference, 1887-93. Glasgow. http://ibpsa.org/proceedings/BS2009/BS09_1887_1893.pdf.

Anderson, Kjell. 2014. Design Energy Simulation for Architects. New York: Routledge.

Atthaillah, Suhartina Wijayanti, and Soraya Masthura Hassan. 2018. "Simulasi Desain Fasad Optimal Terhadap Pencahayaan Alami Pada Gedung Prodi Arsitektur Universitas Malikussaleh." EMARA: Indonesian Journal of Architecture 4 (1): 21-29. https://doi.org/10.29080/emara.v4i1.228.

Dewi, Cynthia Permata, Rong -Yau Huang, and Agung Murti Nugroho. 2013. "Strategi Double Skin Fasade Pada Bangunan Kampus National Central University Dalam Menurunkan Kebutuhan Energi Pendinginan." Review of Urbanism and Architectural Studies 11 (2): 5159. https://doi.org/10.21776/ub.ruas.2013.011.02.6.

Dora, Purnama Esa, and Poppy Firtatwentyna Nilasari. 2011. "Pemanfaatan Pencahayaan Alami Pada Rumah Tinggal Tipe Townhouse Di Surabaya." In Seminar Nasional Living Green: Mensinergikan Kehidupan, Mewujudkan Keberlanjutan. Surabaya. http://repository.petra.ac.id/15247/.

Erlendsson, Örn. 2014. "Daylight Optimization: A Parametric Study of Atrium Design.” Royal Institute of Technology Stockholm. portal.org/smash/get/diva2:723644/FULLTEXT01.pdf.

Fernández, Esquivias, Moreno Rangel, and Fernández Expósito. 2014. “Dynamic Daylight Simulation: New Technics and Metrics to Study Strategies to Reduce Lighting Energy Consumption." In Proceedings of the II International and IV National Congress on Sustainable Construction and EcoEfficient Solutions. https://idus.us.es/xmlui/bitstream/handle/11441/59614/59.pdf?sequence=1.

Groat, Linda, and David Wang. 2013. Architectural Research Method. 2nd ed. Canada: John Wiley \& Sons, Inc.

Lechner, Norberg. 2007. Heating, Cooling, Lighting: Strategi Desain Untuk Arsitektur. 2nd ed. Jakarta: PT Raja Grafindo Persada.

Mangkuto, Rizki A, and F.X. Nugroho Soelami. 2014. "A Pilot Study for Assessing Daylight Availability Metrics in Indonesia." In International Conference on the 15th SENVAR (Sustainable Environmental Architecture) and the 2nd AVAN (Asian Vernacular Architecture Network. Makassar.

Matterson, Maria Leandra González, Ortiz Joana Ferra, Jaume Salom, and Jorge Higuera Portilla. 2013. "Dynamic Daylight Simulation and Visual Comfort Survey in Mediterranean Climate. Case Study in Office Building." In 13th Conference of International Building Performance Simulation Association, 3010-18. www.irec.cat.

Moreno, Maria Beatriz Piderit, and Constanza Yanez Labarca. 2015. "Methodology for Assessing Daylighting Design Strategies in Classroom with a Climate-Based Method." Sustainability (Switzerland) 7 (1): 880-97. https://doi.org/10.3390/su7010880. 
Nabil, A., and J. Mardaljevic. 2005. "Useful Daylight Illuminances: A New Paradigm for Assessing Daylight in Building." Lighting Research and Technology. https://doi.org/10.1191/1365782805li128oa.

Roudsari, Mostapha Sadeghipour, and Michelle Pak. 2013. "Ladybug: A Parametric Environmental Plugin For Grasshopper to Help Designers Create An EnvironmentallyConscious Design." In 13th Conference of International Building Performance Simulation Association, 3128-35. Chambery.

SNI 03-6197, Anonymous. 2000. “Konservasi Energi Pada Sistem Pencahayaan.” Jakarta: Badan Standardisasi Nasional.

Sugiharto, Nathalia Yunita. 2017. "Perbandingan Desain Ruko Di Indonesia Ditinjau Dari Aspek Sosial Dan Pembentukan Komunitas." ARTEKS, Jurnal Teknik Arsitektur 1 (2): 161-70. https://journal.unwira.ac.id/index.php/ARTEKS/article/view/131/58.

Tedeschi, Arturo. 2014. AAD-Algorithms-Aided Design: Parametric Strategies Using Grasshopper. Brienza: Le Penseur.

Vichuda, M, C Pipat, and R Pattana. 2014. "An Enhancement of The Daylighting From SideWindow Using Two-Section Venetian Blind." In 5th International Conference on Sustainable Energy and Environment (SEE 2014), 362-67. 